\title{
Managing Persistent Hypoxemia: what is new? [version 1;
}

\section{peer review: 2 approved]}

\section{Jesús Villar1-3, Carlos Ferrando3,4, Robert M Kacmarek ${ }^{5,6}$}

${ }^{1}$ Keenan Research Center for Biomedical Science at the Li Ka Shing Knowledge Institute, St. Michael's Hospital, Toronto, Canada ${ }^{2}$ Multidisciplinary Organ Dysfunction Evaluation Research Network, Research Unit, Hospital Universitario Dr. Negrin, Las Palmas de Gran Canaria, Spain

${ }^{3}$ CIBER de Enfermedades Respiratorias, Instituto de Salud Carlos III, Madrid, Spain

${ }^{4}$ Department of Anesthesiology, Hospital Clínico Universitario de Valencia, Valencia, Spain

${ }^{5}$ Department of Respiratory Care, Massachusetts General Hospital, Boston, Massuchusetts, USA

${ }^{6}$ Department of Anesthesiology, Harvard Medical School, Boston, Massuchusetts, USA

V1 First published: 13 Nov 2017, 6(F1000 Faculty Rev):1993

https://doi.org/10.12688/f1000research.11760.1

Latest published: 13 Nov 2017, 6(F1000 Faculty Rev):1993

https://doi.org/10.12688/f1000research.11760.1

\section{Abstract}

Mechanical ventilation is the standard life-support technique for patients with severe acute respiratory failure. However, some patients develop persistent and refractory hypoxemia because their lungs are so severely damaged that they are unable to respond to the application of high inspired oxygen concentration and high levels of positive end-expiratory pressure. In this article, we review current knowledge on managing persistent hypoxemia in patients with injured lungs.

\section{Keywords}

mechanical ventilation, severe acute respiratory failure, hypoxemia, persistent hypoxemia

\section{Open Peer Review \\ Approval Status \\ 1 \\ 2 \\ version 1 \\ 13 Nov 2017 \\ Faculty Reviews are review articles written by the prestigious Members of Faculty Opinions. The articles are commissioned and peer reviewed before publication to ensure that the final, published version is comprehensive and accessible. The reviewers who approved the final version are listed with their names and affiliations. \\ 1. Sonal Pannu, The Ohio State University \\ Medical Center, Columbus, USA \\ 2. Charles B Cairns, University of Arizona, \\ Tucson, USA}

Any comments on the article can be found at the end of the article. 
Corresponding author: Jesús Villar (jesus.villar54@gmail.com)

Author roles: Villar J: Conceptualization, Data Curation, Formal Analysis, Funding Acquisition, Supervision, Writing - Original Draft Preparation; Ferrando C: Data Curation, Formal Analysis, Funding Acquisition, Supervision, Validation, Visualization, Writing - Review \& Editing; Kacmarek RM: Conceptualization, Data Curation, Formal Analysis, Supervision, Validation, Visualization, Writing - Review \& Editing

Competing interests: Jesús Villar has received a research grant from Maquet (Solna, Sweden). Robert M. Kacmarek has received research grants from Venner Medical (St Helier, Jersey) and Covidien (Dublin, Republic of Ireland) and is a consultant for Covidien and OrangeMed Inc. (Irvine, CA, USA). Carlos Ferrando declares that he has no competing interests.

Grant information: This work was supported in part by grants from the Instituto de Salud Carlos III, Madrid, Spain (PI13/0119, PI14/00829, PI16/0049, CB06/06/1088) and by the Asociación Científica Pulmón y Ventilación Mecánica. CF is a recipient of a Start-up Young Investigator Award 2015 from the European Society of Anesthesiology.

The funders had no role in study design, data collection and analysis, decision to publish, or preparation of the manuscript.

Copyright: ( $) 2017$ Villar J et al. This is an open access article distributed under the terms of the Creative Commons Attribution License, which permits unrestricted use, distribution, and reproduction in any medium, provided the original work is properly cited.

How to cite this article: Villar J, Ferrando $C$ and Kacmarek RM. Managing Persistent Hypoxemia: what is new? [version 1; peer review: 2 approved] F1000Research 2017, 6(F1000 Faculty Rev):1993 https://doi.org/10.12688/f1000research.11760.1

First published: 13 Nov 2017, 6(F1000 Faculty Rev):1993 https://doi.org/10.12688/f1000research.11760.1 


\section{Introduction and context}

Acute hypoxemic respiratory failure due to acute respiratory distress syndrome (ARDS) is one of the most severe forms of acute lung injury. Caused by direct (pulmonary) or indirect (systemic) insults to the lungs, it is characterized clinically by hypoxemia that does not respond to the administration of high inspiratory concentrations of oxygen $\left(\mathrm{FiO}_{2}\right)$ and by the presence of bilateral pulmonary infiltrates on chest imaging due to high-permeability pulmonary edema ${ }^{1}$. There is no specific pharmacologic treatment for ARDS. An integral part of the supportive therapy of patients with ARDS is the application of invasive mechanical ventilation (MV). The goal of MV is to achieve adequate gas exchange and tissue oxygenation without further damaging the lungs. Since the first description of $\mathrm{ARDS}^{2}$, the use of positive end-expiratory pressure (PEEP) has been adopted as standard practice for the ventilator management of acute respiratory failure. PEEP prevents end-expiratory alveolar collapse.

Most patients with ARDS improve their oxygenation-as assessed by the arterial partial pressure of oxygen/FiO $\left(\mathrm{PaO}_{2} /\right.$ $\mathrm{FiO}_{2}$ ) ratio-after 24 hours of routine intensive care management and after the application of moderate to high levels of PEEP. Today, refractory hypoxemia (which, in most reports, has been defined as having a $\mathrm{PaO}_{2}$ of less than $60 \mathrm{~mm} \mathrm{Hg}$ on a $\mathrm{FiO}_{2}$ of $0.8-1.0$ and PEEP of more than $10 \mathrm{~cm} \mathrm{H}_{2} \mathrm{O}$ for more than 12-24 hours) is an infrequent cause of death ${ }^{3}$. There are no data that link a particular baseline $\mathrm{PaO}_{2} / \mathrm{FiO}_{2}$ to predictable structural changes in the alveolar-capillary membrane at the time of ARDS diagnosis. However, there is recent evidence showing a correlation between lung injury severity and outcome when the $\mathrm{PaO}_{2} / \mathrm{FiO}_{2}$ ratio is assessed under standard ventilatory settings at 24 hours of ARDS onset ${ }^{4}$. Therefore, in this context, although there is no standard definition for persistent hypoxemia in terms of a predetermined $\mathrm{PaO}_{2}$ value under a specific $\mathrm{FiO}_{2}$ and PEEP for a specific period of time, for the purpose of this review persistent hypoxemia exists when the $\mathrm{PaO}_{2} / \mathrm{FiO}_{2}$ is not more than $200 \mathrm{~mm} \mathrm{Hg}$ after 24 hours of MV. The aim of this review is to summarize the current knowledge on a number of techniques that have been shown to improve oxygenation and outcome in ARDS patients with persistent hypoxemia.

\section{Muscle paralysis during lung-protective ventilation}

There is unequivocal evidence that MV can cause or aggravate lung damage - a concept termed ventilator-induced lung injury (VILI). Many of the pathophysiological consequences of VILI resemble those of $\mathrm{ARDS}^{5}$. Since the publication of the landmark paper by the ARDS Network (ARDSnet) in $2000^{6}$ and the pooled data in a meta-analysis of six randomized controlled trials (RCTs) comparing different strategies to apply $\mathrm{PEEP}^{7}$, current recommendations for ventilating patients with ARDS include the application of low tidal volumes (VTs) $(4-8 \mathrm{~mL} / \mathrm{kg}$ predicted body weight, or PBW), PEEP levels that maintain a positive endexpiratory transpulmonary pressure, limiting plateau pressure to less than $30 \mathrm{~cm} \mathrm{H} \mathrm{H}_{2} \mathrm{O}$, limiting driving pressure (plateau pressure minus PEEP) to less than $15 \mathrm{~cm} \mathrm{H}_{2} \mathrm{O}$, and limiting $\mathrm{FiO}_{2}$ to maintain a $\mathrm{PaO}_{2}$ of 55 to $80 \mathrm{~mm} \mathrm{Hg}$ or a peripheral capillary oxygen saturation $\left(\mathrm{SpO}_{2}\right)$ of $90 \%$ to $95 \%$. These five elements are the main components of the framework for "lung-protective ventilation".
However, despite the use of volume- and pressure-limited ventilatory strategies, mechanically ventilated patients with ARDS can be exposed to tidal hyperinflation during spontaneous inspiratory and expiratory efforts, especially in the early stages of ARDS. VT set by clinicians does not always correspond to the true VT delivered, because of double triggering, reverse triggering, and pendelluft, which can occur despite the use of analgesics and sedatives. Papazian et al. ${ }^{8}$ examined the hypothesis that removing spontaneous respiratory efforts in ARDS patients with persistent hypoxemia would improve lung mechanics and decrease oxygen consumption. The authors performed an RCT - the ARDS et Curarisation Systematique (ACURASYS) study-in 340 ARDS patients with a $\mathrm{PaO}_{2} / \mathrm{FiO}_{2}$ of less than 150, a PEEP of at least $5 \mathrm{~cm} \mathrm{H}_{2} \mathrm{O}$, and VT between 6 and $8 \mathrm{~mL} / \mathrm{kg} \mathrm{PBW}$ enrolled within the first 48 hours of ARDS onset. Patients were randomly assigned to receive either a neuromuscular blockade (NMB) agent (cisatracurium) or placebo for 48 hours. The group of patients receiving muscle paralysis had lower adjusted 90-day mortality (primary outcome) and higher ventilator-free days (VFDs) at 28 days than the placebo group. The prevalence of neuromuscular weakness did not differ between groups. It is well known that NMB minimizes work of breathing and patient-ventilator asynchronies in patients with ARDS 9 . However, the results of the ACURASYS study, seven years after its publication, remain controversial. The major criticisms of this trial include a lack of measurement of ventilator asynchrony in the control group, the Kaplan-Meier survival curves separated only after day 14, and, most importantly, the primary end-point of the trial, adjustment of 90-day mortality, achieved statistical significance only with acuity adjustment ${ }^{10}$. In a recent publication ${ }^{11}$, the same group of investigators examined the effects of $\mathrm{NMB}$ on transpulmonary pressure in a small pilot RCT of 24 patients with persistent ARDS and found that NMB could exert beneficial effects in patients with moderate ARDS by limiting expiratory efforts. Although these early data are supportive of the use of NMB, additional verification of early NMB in ARDS is required if widespread implementation is to occur. A new RCT is currently enrolling patients with moderate to severe ARDS and is powered for validating and assessing the efficacy and safety of early NMB in reducing morbidity and 90-day mortality ${ }^{12}$. This trial is not an exact replication of ACURASYS since both groups of patients will receive a high PEEP open-lung ventilation approach. If the trial yields a positive result, it will establish early NMB as a standard approach in the management of patients with moderate to severe ARDS.

\section{Prone ventilation}

ARDS is a histopathologically heterogeneous disease process ${ }^{13}$. Recruitability of alveolar space with PEEP is also heterogeneous both between patients and within the lungs. Changes in posture can have profound effects on the pulmonary function of critically ill patients. Therapeutic alteration in the distribution of delivered gas for mitigating VILI is the basis of both prone ventilation and recruitment maneuvers (RMs). Prone positioning should be viewed as an adjunctive therapy to be used in combination with other accepted therapies in the management of critically ill patients with persistent hypoxemia. However, although it is widely known to improve oxygenation in patients with ARDS and shown to aid in alveolar recruitment, controversy over its use in clinical 
practice continues. Ventilating an ARDS patient in a prone position provides several physiological advantages for the management of persistent hypoxemia, including an increase in functional residual capacity, a change in regional diaphragm motion, better matching of ventilation to perfusion, removal of the heart's weight from the lung, and improved secretion clearance ${ }^{14}$. In general, prone ventilation can be performed safely if health-care staff are appropriately trained. Although there are sufficient data to conclude that oxygenation frequently improves when patients with ARDS are turned prone, several studies on prone ventilation produced conflicting results about its efficacy in persistent hypoxemia, until a meta-analysis suggested benefits specifically in the most hypoxemic patients receiving lung-protective $\mathrm{MV}^{15}$. As with $\mathrm{NMB}$, there is only one large positive RCT demonstrating survival benefit ${ }^{16}$ of prone ventilation in moderate to severe ARDS, the "Proning Severe ARDS Patients" (PROSEVA) trial ${ }^{17}$. The investigators randomly assigned 466 patients with persistent ARDS (as defined by a $\mathrm{PaO}_{2} / \mathrm{FiO}_{2}$ of less than $150 \mathrm{~mm} \mathrm{Hg}$ with $\mathrm{FiO}_{2}$ of less than 0.6 and PEEP of at least $5 \mathrm{~cm} \mathrm{H}_{2} \mathrm{O}$ ) to undergo pronepositioning sessions of at least 16 hours or to be left in the supine position. In both groups, patients were ventilated using the low PEEP-FiO , table from the ARDSnet trial ${ }^{6}$. The 28-day mortality rates were $32.8 \%$ in the supine group and $16.0 \%$ in the prone group $(P<0.001)$, a difference that persisted at 90 days after random assignment $(41.0 \%$ in the supine group versus $23.6 \%$ in the prone group, $P<0.001)$.

Proponents of prone ventilation (which usually also requires NMB) suggest that the approach taken in PROSEVA was a refinement of a technique that finally got it right when patients were ventilated with a VT of not more than $8 \mathrm{~mL} / \mathrm{kg} \mathrm{PBW}{ }^{18}$. Detractors suggest that the large treatment effect seen (almost an absolute $20 \%$ difference) was too good to be true ${ }^{16,19}$. Of note, patients assigned to the supine position were ventilated during the first three days with very low PEEP levels (mean of $9 \pm 3 \mathrm{~cm}$ $\mathrm{H}_{2} \mathrm{O}$ ) for patients with severe ARDS. An additional, large validation RCT is required to confirm these findings if widespread implementation of prone ventilation in early stages of persistent ARDS is to occur. However, such a trial should ensure that the control arm receives a high PEEP open-lung ventilation approach.

\section{Driving pressure}

Recently, attention regarding VILI has focused on driving pressure (plateau pressure minus PEEP). Amato et al..$^{20}$, in an analysis of nine pre-existing RCTs, determined that driving pressure had a greater impact on mortality in persistent ARDS than VT, plateau pressure, or PEEP. They identified a cut-point of $15 \mathrm{~cm} \mathrm{H}_{2} \mathrm{O}$. That is, the risk of death increased as driving pressure exceeded $15 \mathrm{~cm} \mathrm{H}_{2} \mathrm{O}$. Subsequently, Villar et al. ${ }^{21}$, in a reanalysis of data from three epidemiologic studies in ARDS where all patients were ventilated with a lung-protective strategy, determined that driving pressure and plateau pressure had essentially the same impact on mortality with a driving pressure cut-point of $18 \mathrm{~cm} \mathrm{H_{2 }}$ O. In addition, Chiumello et al. ${ }^{22}$ identified a strong correlation between airway driving pressure and transpulmonary driving pressure (calculated as end-inspiratory transpulmonary pressure minus end-expiratory transpulmonary pressure). It seems physiologically sound to be concerned with driving pressure. The exact cut-point is still open to debate but all would agree that the lower the driving pressure the better the patient outcome.

$\mathrm{FiO}_{2}$

Oxygen is routinely administered to almost all critically ill patients. Although oxygen therapy can be lifesaving, it is not without serious effects. Too little oxygen is problematic but so is too much $^{23}$. Rachmale et al. $^{24}$ assessed the effects of excessive oxygen exposure (defined as $\mathrm{FiO}_{2}$ of more than 0.5 despite $\mathrm{SpO}_{2}$ of more than 92\%) in 210 mechanically ventilated ARDS patients on pulmonary outcomes. The authors found that prolonged exposure to excessive oxygen was associated with worsening lung function (worse oxygenation index and more days on MV), longer intensive care unit (ICU) stay, and longer hospital stay. In a subsequent RCT, Girardis et al. ${ }^{25}$ randomly assigned mechanically ventilated medical/surgical patients to receive conservative oxygen therapy (target $\mathrm{PaO}_{2}$ of 70 to $100 \mathrm{~mm} \mathrm{Hg}$ and $\mathrm{SpO}_{2}$ of $94 \%$ to $98 \%$ ) or standard oxygen therapy (target $\mathrm{PaO}_{2}$ of up to $150 \mathrm{~mm} \mathrm{Hg}$ and $\mathrm{SpO}_{2}$ of $97 \%$ to $100 \%$ ). All other variables associated with care were standardized across groups. They found a significant difference in ICU mortality $(11.6 \%$ conservative versus $20.2 \%$ standard), hospital and 60-day mortality, favoring conservative oxygen therapy. Thus, it is in the patients' best interest to maintain the $\mathrm{PaO}_{2}$ of 55 to $80 \mathrm{~mm} \mathrm{Hg}$ and $\mathrm{SpO}_{2}$ of $90 \%$ to $95 \%$ as defined by the ARDSnet protocol ${ }^{6}$ to eliminate the effect of oxygenation status on outcome. Additional validation studies are in the process of being published.

\section{Recruitment maneuvers and transpulmonary pressure}

Imaging studies have provided insight into the ARDS lung ${ }^{26}$. Classic computed tomography (CT) has shown that some lung regions in ARDS appear radiographically to be relatively normal but that some other areas are partially collapsed and unable to participate in gas exchange. The concept of the "baby lung" has led to the understanding of potential interaction of MV settings and patient outcome and often using CT as a reference for applying personalized ventilatory management in patients with severe $\operatorname{ARDS}^{27}$. Collapsed or atelectatic areas of the lung can be re-expanded by the application of brief periods of sustained high-inflation pressure followed by the application of adequate levels of PEEP to maintain the new re-aerated region open ${ }^{28}$. These RMs are intended to re-open collapsed alveoli and to attenuate the injurious effects of the repetitive opening and closing of alveolar units, promoting lung protection by reducing lung stress in areas of heterogeneity. Three commonly used RMs are sighs, sustained inflations, and extended sighs ${ }^{29}$. PEEP prevents lung unit collapse at end expiration. Much controversy exists over the benefits of RMs in persistent ARDS. A systematic review of 40 studies $^{30}$ showed that RMs increased oxygenation and improved respiratory system mechanics, but little information about the long-term effects and usefulness of these interventions was available until recently. The major differences seem to be based on the selection of PEEP post-RM that sustains the benefit of RMs.

In a pilot RCT that was performed from 2007 to 2013 in 200 ARDS patients with persistent hypoxemia and that compared the 
ARDSnet protocol ${ }^{6}$ using low levels of PEEP with an open-lung approach-which involves RMs and a decremental PEEP trial for identifying the PEEP level associated with maximum dynamic compliance-Kacmarek et al. ${ }^{31}$ found that the open-lung approach ventilatory strategy improved oxygenation and respiratory system mechanics without detrimental effects on 60-day mortality (33\% in the ARDSnet group versus $29 \%$ in the open-lung approach), VFDs, or barotrauma. This trial supported the need for a large RCT using RMs in association with PEEP titrated by compliance of the respiratory system to test whether this approach is able to increase survival in patients with persistent ARDS. Such a trial has been finalized recently and we await its results ${ }^{32}$.

A more recent approach for titrating PEEP is to optimize the end-expiratory transpulmonary pressure (PEEP minus pleural pressure). Pleural pressure, estimated via esophageal manometry, has been shown to differ considerably among patients with acute respiratory failure, indicating that lung and chest wall mechanics both contribute substantially and unpredictably to respiratory system mechanics and airway pressures measured by the ventilator $^{33}$. During RM and PEEP, the distending pressure delivered by the ventilator consists of two components: one to inflate the lung and one to expand the chest wall. Accordingly, RM and PEEP can be titrated safely to an optimal transpulmonary pressure target. In a small pilot RCT of 61 ARDS patients with persistent hypoxemia, in which the use of ARDSnet PEEP-FiO table was compared with an open-lung approach that included esophageal pressure-guided setting of PEEP (EPVent trial), targeting a positive end-expiratory transpulmonary pressure (PEEP minus esophageal pressure) showed that esophagealguided PEEP was associated with improved oxygenation and, after adjusting for illness severity, improved survival ${ }^{34}$. A multicenter validation trial powered (estimated sample size of 200 patients with ARDS) for patient-centered outcome (a composite outcome of mortality and VFDs at 28 days) is ongoing ${ }^{35}$.

Of note, esophageal pressure-guided MV translated into higher PEEP application (18 versus $12 \mathrm{~cm} \mathrm{H}_{2} \mathrm{O}$ on day 1 ), demonstrating that commonly used PEEP levels by clinicians are inadequate for optimal MV in patients with ARDS. In a small nonrandomized interventional study in 14 critically ill, mechanically ventilated, morbidly obese patients, Pirrone et al..$^{36}$ evaluated both methods of titrating PEEP (that is, RM followed by a decremental PEEP trial versus RM followed by targeting a positive endexpiratory transpulmonary pressure) and observed that the two methods of determining optimal PEEP identified similar PEEP levels $\left(20.7 \pm 4.0\right.$ versus $\left.21.3 \pm 3.8 \mathrm{~cm} \mathrm{H}_{2} \mathrm{O}\right)$ but that the PEEP levels set by the clinicians $\left(11.6 \pm 2.9 \mathrm{~cm} \mathrm{H}_{2} \mathrm{O}\right)$ were associated with lower lung volumes, worse elastic properties of the lung, and lower oxygenation.

\section{Extracorporeal membrane oxygenation}

This technique was originally applied to patients with severe acute respiratory failure in which it was impossible to provide adequate oxygenation by $\mathrm{MV}^{37}$. Since $\mathrm{MV}$ is reliant on functional lung units for gas diffusion, it would be unable to provide respiratory support when there is no minimum amount of functional alveoli. Substituting alveolar gas exchange by extracorporeal membrane oxygenation (ECMO) or extracorporeal carbon dioxide $\left(\mathrm{CO}_{2}\right)$ removal would allow a marked reduction of VT, respiratory rate, and $\mathrm{FiO}_{2}$, reducing the risk of VILI. To provide gas exchange during ECMO, a portion of the cardiac output must go through the ECMO circuit via the femoral, saphenous, or jugular veins. During ECMO, $\mathrm{CO}_{2}$ is removed by the extracorporeal circuit with MV maintained at low ventilatory rates, high PEEP levels, and with VT to maintain a plateau pressure below $29 \mathrm{~cm} \mathrm{H}_{2} \mathrm{O}$. In the last few years, there have been considerable advances in extracorporeal life support, and despite widespread and growing use worldwide in patients with $\mathrm{ARDS}^{38}$, at present the evidence base for ECMO in ARDS is scarce, consisting of case series, observational cohorts, and only one RCT.

A recent $\mathrm{RCT}$, referred to as the CESAR (Conventional ventilatory support versus Extracorporeal membrane oxygenation for Severe Adult Respiratory failure) trial, assessed the effectiveness of ECMO in 180 patients with severe $\mathrm{ARDS}^{39}$. However, rather than directly assessing ECMO in refractory hypoxemia, investigators compared ECMO management at a referring center with MV management at tertiary centers. The 6-month survival rate was higher in patients at the ECMO center than in those patients managed with MV at participating centers $(63 \%$ versus $47 \%, P=0.03)$. Major concerns with the reported results included (i) patients allocated to MV were treated with conventional MV or with high-frequency ventilation, (ii) $30 \%$ of patients in the control group were not ventilated with a lung-protective strategy, (iii) the ECMO center did not treat patients randomly assigned to the conventional management group, (iv) no data regarding ventilation at study entry and during the MV period were presented, and (v) many patients randomly assigned to ECMO never received ECMO. A multicenter trial for severe ARDS comparing ECMO with a protocolized lung-protective MV strategy is ongoing ${ }^{40}$.

There are some studies suggesting the combined use of ECMO with prone positioning in severe ARDS. Guervilly et al. ${ }^{41}$ reported their experience in 15 patients with severe ARDS who were turned to a prone position during ECMO therapy because of at least one of the three following conditions: $\mathrm{PaO}_{2} / \mathrm{FiO}_{2}$ of less than 70 on maximal oxygenation, plateau pressure of more than $32 \mathrm{~cm}$ $\mathrm{H}_{2} \mathrm{O}$, or failure to wean ECMO after at least 10 days on ECMO support. The authors found significant improvement in oxygenation and no complications related to proning. Also, Kredel et $a l .{ }^{42}$ reported their experience of positional therapy in a retrospective cohort of nine patients with severe ARDS treated with ECMO. Positioning therapy included complete prone, partially prone, and continuous lateral rotational therapy. During the first three days, the oxygenation index and lung compliance improved significantly, suggesting that positioning therapy can be performed safely in patients with ARDS treated with ECMO, providing appropriate precautions and a very experienced team.

\section{Implications for clinical practice}

In summary, the most critical factor in managing the patient with ARDS is the initiation of lung-protective MV immediately upon intubation. In most patients with severe ARDS, a period of NMB agents with sedatives/narcotics is needed to gain stability of the cardiovascular/respiratory systems that are maximally 
stressed. Whether NMBs need to be administered for 48 hours in all patients is still open to debate, but some period from 8 to 48 hours seems beneficial in patients with severe ARDS. Once patients are stabilized, the lung should be recruited and PEEP set by a decremental best compliance PEEP trial or by PEEP establishing a positive end-expiratory transpulmonary pressure (both techniques resulting in the same PEEP). Once PEEP is set, VT is adjusted to 4 to $8 \mathrm{~mL} / \mathrm{kg}$ PBW to maintain a driving pressure of less than $15 \mathrm{~cm} \mathrm{H}_{2} \mathrm{O}$ and a plateau pressure of less than $30 \mathrm{~cm}$ $\mathrm{H}_{2} \mathrm{O}$ with ventilator rate increased to manage partial pressure of carbon dioxide in arterial blood $\left(\mathrm{PaCO}_{2}\right)$. Finally, the $\mathrm{FiO}_{2}$ should be decreased to the lowest level that maintains the $\mathrm{PaO}_{2}$ of 55 to $80 \mathrm{~mm} \mathrm{Hg}$ and the $\mathrm{SpO}_{2}$ of $88 \%$ to $95 \%$. In patients in whom persistent hypoxemia persists, prone positioning should be considered, and in those in whom refractory hypoxemia persists after proning, ECMO should be considered. Many of the above steps in managing severe ARDS are still considered controversial since they are supported only by single RCTs, non-RCTs, or retrospective analysis. However, until data from ongoing studies are available, this seems to be the most beneficial and unifying approach to the management of the patient with severe ARDS and persistent hypoxemia.

\section{Abbreviations}

ACURASYS, ARDS et Curarisation Systematique; ARDS, acute respiratory distress syndrome; ARDSnet, ARDS network; $\mathrm{CO}_{2}$, carbon dioxide; CT, computed tomography; ECMO, extracorporeal membrane oxygenation; $\mathrm{FiO}_{2}$, fraction of inspired oxygen;
ICU, intensive care unit; MV, mechanical ventilation; NMB, neuromuscular blockade; $\mathrm{PaO}_{2}$, arterial partial pressure of oxygen; PBW, predicted body weight; PEEP, positive end-expiratory pressure; PROSEVA, Proning Severe ARDS Patients; RCT, randomized controlled trial; $\mathrm{RM}$, recruitment maneuver; $\mathrm{SpO}_{2}$, peripheral capillary oxygen saturation; VFD, ventilator-free day; VILI, ventilator-induced lung injury; VT, tidal volume.

Competing interests

Jesús Villar has received a research grant from Maquet (Solna, Sweden). Robert M. Kacmarek has received research grants from Venner Medical (St Helier, Jersey) and Covidien (Dublin, Republic of Ireland) and is a consultant for Covidien and OrangeMed Inc. (Irvine, CA, USA). Carlos Ferrando declares that he has no competing interests.

\section{Grant information}

This work was supported in part by grants from the Instituto de Salud Carlos III (Madrid, Spain) (PI13/0119, PI14/00829, PI16/00049, and CB06/06/1088) and by the Asociación Científica Pulmón y Ventilación Mecánica. Carlos Ferrando is a recipient of a Start-up Young Investigator Award 2015 from the European Society of Anesthesiology.

The funders had no role in study design, data collection and analysis, decision to publish, or preparation of the manuscript.
1. Villar J: What is the acute respiratory distress syndrome? Respir Care. 2011; 56(10): 1539-45.

PubMed Abstract | Publisher Full Text

2. Ashbaugh DG, Bigelow DB, Petty TL, et al.: Acute respiratory distress in adults. Lancet. 1967; 2(7511): 319-23.

PubMed Abstract | Publisher Full Text

3. Villar J, Kacmarek RM: Rescue strategies for refractory hypoxemia: a critical appraisal. F1000 Med Rep. 2009; 1: pii: 91.

PubMed Abstract | Publisher Full Text | Free Full Text

4. Villar J, Blanco J, del Campo R, et al:: Assessment of $\mathrm{PaO}_{2} / \mathrm{FiO}$ for stratification of patients with moderate and severe acute respiratory distress syndrome. BMJ Open. 2015; 5(3): e006812.

PubMed Abstract | Publisher Full Text | Free Full Text

5. Villar J, Slutsky AS: Is acute respiratory distress syndrome an iatrogenic disease? Crit Care. 2010; 14(1): 120

PubMed Abstract | Publisher Full Text | Free Full Text

6. F Acute Respiratory Distress Syndrome Network, Brower RG, Matthay MA, et al. Ventilation with lower tidal volumes as compared with traditional tidal volumes for acute lung injury and the acute respiratory distress syndrome. $N$ Engl $J$ Med. 2000; 342(18): 1301-8.

PubMed Abstract | Publisher Full Text | F1000 Recommendation

7. Phoenix SI, Paravastu S, Columb M, et al.: Does a higher positive end expiratory pressure decrease mortality in acute respiratory distress syndrome? A systematic review and meta-analysis. Anesthesiology. 2009; 110(5): 1098-1105 PubMed Abstract | Publisher Full Text

8. F Papazian L, Forel J, Gacouin A, et al:: Neuromuscular blockers in early acute respiratory distress syndrome. N Engl J Med. 2010; 363(12): 1107-16. PubMed Abstract | Publisher Full Text | F1000 Recommendation

9. Light RW, Bengfort JL, George RB: The adult respiratory distress syndrome and pancuronium bromide. Anesth Analg. 1975; 54(2): 219-23. PubMed Abstract | Publisher Full Text
10. Yegneswaran B, Murugan R: Neuromuscular blockers and ARDS: thou shalt not breathe, move, or die! Crit Care. 2011; 15(5): 311 PubMed Abstract | Publisher Full Text | Free Full Text

11. F Guervilly C, Bisbal M, Forel JM, et al.: Effects of neuromuscular blockers on transpulmonary pressures in moderate to severe acute respiratory distress syndrome. Intensive Care Med. 2017; 43(3): 408-18. PubMed Abstract | Publisher Full Text | F1000 Recommendation

12. Schoenfeld DA: Reevaluation of Systemic Early Neuromuscular Blockade (ROSE). ClinicalTrials.gov, NCT02509078, 2015. Reference Source

13. Guerin C, Bayle F, Leray V, et al:: Open lung biopsy in nonresolving ARDS frequently identifies diffuse alveolar damage regardless of the severity stage and may have implications for patient management. Intensive Care Med. 2015; 41(2): 222-30. PubMed Abstract | Publisher Full Text

14. Lamm WJ, Graham MM, Albert RK: Mechanism by which the prone position improves oxygenation in acute lung injury. Am J Respir Crit Care Med. 1994 150(1): 184-93.

PubMed Abstract | Publisher Full Text

15. F Sud S, Friedrich JO, Taccone $\mathrm{P}$, et al.: Prone ventilation reduces mortality in patients with acute respiratory failure and severe hypoxemia: systematic review and meta-analysis. Intensive Care Med. 2010; 36(4): 585-99. PubMed Abstract | Publisher Full Text | F1000 Recommendation

16. Tonelli AR, Zein J, Adams J, et al: Effects of interventions on survival in acute respiratory distress syndrome: an umbrella review of 159 published randomized trials and 29 meta-analyses. Intensive Care Med. 2014; 40(6): 769-87. PubMed Abstract | Publisher Full Text | Free Full Text

17. F Guérin $\mathrm{C}$, Reignier J, Richard JC, et al:: Prone positioning in severe acute respiratory distress syndrome. N Engl J Med. 2013; 368(23): 2159-68. PubMed Abstract | Publisher Full Text | F1000 Recommendation 
18. Beitler JR, Shaefi S, Montesi SB, et al.: Prone positioning reduces mortality from acute respiratory distress syndrome in the low tidal volume era: a metaanalysis. Intensive Care Med. 2014; 40(3): 332-41. PubMed Abstract | Publisher Full Text | Free Full Text

19. Villar J, Kacmarek RM, Guérin C: Clinical trials in patients with the acute respiratory distress syndrome: burn after reading. Intensive Care Med. 2014; 40(6): 900-2.

PubMed Abstract | Publisher Full Text

20. F Amato MB, Meade MO, Slutsky AS, et al.: Driving pressure and survival in the acute respiratory distress syndrome. N Engl J Med. 2015; 372(8): 747-55. PubMed Abstract | Publisher Full Text | F1000 Recommendation

21. Villar J, Martín-Rodríguez C, Domínguez-Berrot AM, et al.: A Quantile Analysis of Plateau and Driving Pressures: Effects on Mortality in Patients With Acute Respiratory Distress Syndrome Receiving Lung-Protective Ventilation. Crit Care Med. 2017; 45(5): 843-50.

PubMed Abstract | Publisher Full Text

22. $\mathrm{F}$ Chiumello $\mathrm{D}$, Carlesso $\mathrm{E}$, Brioni $\mathrm{M}$, et al: : Airway driving pressure and lung stress in ARDS patients. Crit Care. 2016; 20(1): 276

PubMed Abstract | Publisher Full Text | Free Full Text | F1000 Recommendation

23. Villar J, Kacmarek RM: Oxygen: Breath of Life or Kiss of Death. Crit Care Med. 2017; 45(2): 368-9.

PubMed Abstract | Publisher Full Text

24. F Rachmale S, Li G, Wilson G, et al:: Practice of excessive $F(I O(2))$ and effect on pulmonary outcomes in mechanically ventilated patients with acute lung injury. Respir Care. 2012; 57(11): 1887-93. PubMled Abstract | F1000 Recommendation

25. F Girardis M, Busani S, Damiani E, et al.: Effect of Conservative vs Conventional Oxygen Therapy on Mortality Among Patients in an Intensive Care Unit: The Oxygen-ICU Randomized Clinical Trial. JAMA. 2016; 316(15): 1583-9.

PubMed Abstract | Publisher Full Text | F1000 Recommendation

26. F Bellani G, Rouby JJ, Constantin JM, et al.: Looking closer at acute respiratory distress syndrome: the role of advanced imaging techniques. Curr Opin Crit Care. 2017; 23(1): 30-7.

PubMed Abstract | Publisher Full Text | F1000 Recommendation

27. Gattinoni L, Pesenti A: The concept of "baby lung". Intensive Care Med. 2005 31(6): 776-84.

PubMed Abstract | Publisher Full Text

28. Girgis $\mathrm{K}$, Hamed $\mathrm{H}, \mathrm{Khater} \mathrm{Y}$, et al:: A decremental PEEP trial identifies the PEEP level that maintains oxygenation after lung recruitment. Respir Care. 2006; 51(10): 1132-9. PubMed Abstract

29. Guerin C, Debord S, Leray V, et al.: Efficacy and safety of recruitment maneuvers in acute respiratory distress syndrome. Ann Intensive Care. 2011; 1(1): 9 PubMed Abstract | Publisher Full Text | Free Full Text

30. Fan E, Wilcox ME, Brower RG, et al:: Recruitment maneuvers for acute lung injury: a systematic review. Am J Respir Crit Care Med. 2008; 178(11): 1156-63. PubMed Abstract | Publisher Full Text

31. Kacmarek RM, Villar J, Sulemanji D, et al.: Open Lung Approach for the Acute Respiratory Distress Syndrome: A Pilot, Randomized Controlled Trial. Crit Care Med. 2016; 44(1): 32-42.

PubMed Abstract | Publisher Full Text

32. Cavalcanti AB: Alveolar Recruitment for acute respiratory distress syndrome Trial (ART). ClinicalTrials.gov, NCT01374022, 2011. Reference Source

33. Talmor D, Sarge T, O'Donnell CR, et al.: Esophageal and transpulmonary pressures in acute respiratory failure. Crit Care Med. 2006; 34(5): 1389-94. PubMed Abstract | Publisher Full Text | Free Full Text

34. F Talmor D, Sarge T, Malhotra A, et al:: Mechanical ventilation guided by esophageal pressure in acute lung injury. N Engl J Med. 2008; 359(20): 2095-104.

PubMed Abstract | Publisher Full Text | Free Full Text | F1000 Recommendation

35. Talmor DS: EPVent 2- A phase II study of mechanical ventilation directed by transpulmonary pressures (EPVent2). ClinicalTrials.gov, NCT01681225, 2012. Reference Source

36. Pirrone M, Fisher D, Chipman D, et al.: Recruitment Maneuvers and Positive End-Expiratory Pressure Titration in Morbidly Obese ICU Patients. Crit Care Med. 2016; 44(2): 300-7. PubMed Abstract | Publisher Full Text

37. Egan TM, Duffin J, Glynn MF, et al.: Ten-year experience with extracorporeal membrane oxygenation for severe respiratory failure. Chest. 1988; 94(4): 681-7. PubMed Abstract | Publisher Full Text

38. Morris AH: Exciting new ECMO technology awaits compelling scientific evidence for widespread use in adults with respiratory failure. Intensive Care Med. 2012; 38(2): 186-8.

PubMed Abstract | Publisher Full Text

39. F Peek GJ, Mugford M, Tiruvoipati R, et al:: Efficacy and economic assessment of conventional ventilatory support versus extracorporea membrane oxygenation for severe adult respiratory failure (CESAR): a multicentre randomised controlled trial. Lancet. 2009; 374(9698): 1351-63. PubMed Abstract | Publisher Full Text | F1000 Recommendation

40. Combes A: Extracorporeal Membrane Oxygenation for Severe Acute Respiratory Distress Syndrome (EOLIA). ClinicalTrials.gov, NCT01470703, 2011. Reference Source

41. F Guervilly C, Hraiech S, Gariboldi V, et al:: Prone positioning during venovenous extracorporeal membrane oxygenation for severe acute respiratory distress syndrome in adults. Minerva Anestesiol. 2014; 80(3): 307-13. PubMed Abstract | F1000 Recommendation

42. $\mathrm{F}$ Kredel M, Bischof L, Wurmb TE, et al:: Combination of positioning therapy and venovenous extracorporeal membrane oxygenation in ARDS patients. Perfusion. 2014; 29(2): 171-7.

PubMed Abstract | Publisher Full Text | F1000 Recommendation 


\section{Open Peer Review}

\section{Current Peer Review Status:}

\section{Editorial Note on the Review Process}

Faculty Reviews are review articles written by the prestigious Members of Faculty Opinions. The articles are commissioned and peer reviewed before publication to ensure that the final, published version is comprehensive and accessible. The reviewers who approved the final version are listed with their names and affiliations.

\section{The reviewers who approved this article are:}

\section{Version 1}

\section{Charles B Cairns}

Department of Emergency Medicine, University of Arizona, Tucson, USA

Competing Interests: No competing interests were disclosed.

\section{Sonal Pannu}

Division of Pulmonary, Allergy, Critical Care \& Sleep Medicine, The Ohio State University Medical Center, Columbus, USA

Competing Interests: No competing interests were disclosed.

The benefits of publishing with F1000Research:

- Your article is published within days, with no editorial bias

- You can publish traditional articles, null/negative results, case reports, data notes and more

- The peer review process is transparent and collaborative

- Your article is indexed in PubMed after passing peer review

- Dedicated customer support at every stage

For pre-submission enquiries, contact research@f1000.com 